\title{
Designing virtual team projects with accessibility in mind: an illustrative example of cross-cultural student collaboration
}

\author{
Sushil K. Oswal' ${ }^{1}$ Zsuzsanna B. Palmer², and Rita Koris ${ }^{3}$
}

Abstract

W e report on the results of the second-year study of an interdisciplinary, international collaboration among students and instructors at one European and two US universities. The purpose of the study was to examine whether our changing four pedagogical elements from Year 1 to Year 2 affected the students' perceptions of learning. The primary purpose of the pedagogical collaboration itself was to involve students in authentic collaborative learning activities intended to support them in developing an understanding of disability and accessibility concepts in a business context. Students in a business English course proposed start-up companies and created business plans for their ventures. Students in an introductory professional writing course designed websites for the planned businesses, while students in a gateway technical communication course served as advisors to the other two classes regarding how to make the proposed businesses and websites accessible to people with disabilities. We collected quantitative and qualitative data through pre- and post-project surveys. These data were supplemented with qualitative data from student interactions, student submissions (work products), video conference meeting minutes, and instructors' notes. The analysis revealed that students reported increased awareness of disability and openness to finding solutions for accessibility issues.

1. University of Washington, United States; oswal@u.washington.edu; https://orcid.org/0000-0003-2338-5911

2. Grand Valley State University, United States; palmerzs@gvsu.edu; https://orcid.org/0000-0001-8152-4823

3. Pázmány Péter Catholic University, Hungary; koris.rita@btk.ppke.hu; https://orcid.org/0000-0003-1912-8744

How to cite this article: Oswal, S. K., Palmer, Z. B., \& and Koris, R. (2021). Designing virtual team projects with accessibility in mind: an illustrative example of cross-cultural student collaboration. Journal of Virtual Exchange, 4(SI-IVEC2020), 1-27. https://doi.org/10.21827/jve.4.37192 
Keywords: client-provider relationships; distributed teams; inclusive design; interdisciplinary collaboration; technical and professional communication; virtual exchange.

\section{Introduction}

Global trends toward distributed work in multinational organizations, and the rapid digitalization of the 21st century, have posed new challenges to higher education institutions and reshaped our educational ecosystems (European Commission, 2020; European Political Strategy Centre, 2017; World Economic Forum, 2016). The increasing emphasis on internationalization, the necessity to develop digital and transversal skills, recognition of the importance of multidisciplinarity (also described as interdisciplinarity), and calls to implement innovative pedagogies represent challenges for universities but open new opportunities for educators and students in higher education. To take on these new challenges and seize emerging opportunities, faculty are developing and offering innovative courses to address the internationalization of the curriculum by employing new pedagogical practices (Leask, 2015). Several international and European projects, for example Erasmus+ Virtual Exchange and the Soliya Connect Program have been initiated in recent decades, offering new alternatives for internationalization at home and providing opportunities for university faculty and students to gain international experience in virtual spaces (Elliott-Gower \& Hill, 2015; Garcés \& O’Dowd, 2021; Hauck, 2019; Štefl, 2019).

While there are many different models for collaboration across cultural boundaries, courses, and disciplines, and the term virtual exchange has been brought into play to account for a variety of contexts, the recent trend has been to characterize virtual exchange programs as experiential learning projects structured around student activities and assignments. Garcés and O'Dowd (2021) argue that "in contrast to many forms of virtual learning, which are based on the transfer of information through video lectures and online content, [virtual exchange] is based on student-centered, collaborative approaches to learning where knowledge and intercultural understanding are constructed through learner-to-learner interaction and negotiation” (p. 284). To study the effectiveness of student-centered virtual exchanges and faculty collaborations, instructors have designed diverse research projects (see Anderson et al., 2010; Guth \& Helm, 2010; Maylath, Vandepitte, \& Mousten, 2008; O’Dowd, 2016, 2018; Sadler \& Dooly, 2016; Starke-Meyerring \& Andrews, 2006; Ullom, 2017). Most virtual exchange projects are embedded within foreign language instruction for improving students' linguistic and intercultural communication competence (see Belz, 2005; Bueno-Alastuey \& Kleban, 2016; Guth \& Helm, 2010; Helm, 2015; O’Dowd \& O’Rourke, 2019, for examples) and in a variety of teacher education programs (Walshe \& Driver, 2019). Other cross-cultural collaborative 
projects follow the content and language integrated learning approach where the focus lies more on teaching a specific subject matter related to the students' discipline, which may be complemented with cross-cultural experiences (see Cunningham, 2019; Duus \& Cooray, 2014; Gonzalez-Perez et al., 2014; Hernández-Nanclares, Mato, Díaz, \& Koris, 2019; Koris \& Vuylsteke, 2020). In spite of this trend toward internationalization and the promotion of multidisciplinary approaches in European tertiary education, such collaboration projects are not yet widespread in the university curricula of some countries within the European Union and these projects are under reported in the literature (Hernández-Nanclares et al., 2019; Palmer, Oswal, \& Koris, 2020; Roy, Schlosser, \& Pasek, 2020).

The next generation of graduates will need to exercise interdisciplinary thinking to synthesize the complexities of intertwined disciplines to succeed in the globalized workplace. Spelt et al. (2009) defined interdisciplinary thinking as "the capacity to integrate knowledge of two or more disciplines to produce a cognitive advancement in ways that would have been impossible or unlikely through single disciplinary means” (p. 365). European policy makers seem to suggest that students in the globally networked workplace will be working with interdisciplinary teams which would require openness to understanding the ways of thinking of people from other disciplines and professional backgrounds. Thus, interdisciplinary thinking is a marketable skill that students must develop and practice (Jacob, 2015).

As educators from three different disciplines, at different universities, teaching graduate and undergraduate students from two countries, we have designed and taught an ambitious interdisciplinary virtual exchange that has now completed its second iteration. Through this experience and the data collected from it, we have found that such collaborations can answer the call for projects that promote both interdisciplinary experience and student learning around issues of disability awareness and accessibility (see Palmer et al., 2020 for discussion of the results of the first year of this virtual exchange.) As disability laws across the European Union (Waddington \& Lawson, 2010) and in the United States (Americans with Disabilities Act, 1990) ascribe equal rights to disabled persons, accessibility know-how is not only a civic duty but is also a practical business skill.

Oswal (2013) defined accessibility in the context of disability as

"the ability to use, enjoy, perform, work on, avail of, and participate in a resource, technology, activity, opportunity, or product at an equal or comparable level with others. Separate is not equal and before or after the fact is also not equal” (n.p.).

In line with this broad definition, the term accessibility throughout this study refers to designs inclusive of disabled users. We describe the next iteration of an international, interdisciplinary 
collaboration, discuss student perspectives on the effectiveness of the focus of the project on accessibility for the disabled, and discuss lessons learned that will inform future iterations of this pedagogical approach.

\section{The international collaboration}

As with the first iteration, the project involved collaboration across three courses, one each in Hungary, Michigan (US), and Washington (state; US). We developed a pedagogical design that involved students in team activities, based on a simulated client-provider relationship (Blakeslee, 2001; Yu, 2010). Students were assigned to teams of three to four, each with a specific mission or task. The teams consisted of students in the same course and were formed by the instructors to reflect the size and demographic diversity of their classes. All of the teams at each university had the same task. In total, there were eight teams with Task A (devising business plans, Hungarian teams), eight teams with Task B (designing websites, Michigan), and eight teams with Task C (advising the two teams at the other two institution in their group about accessibility, Washington). The teams were then placed into $\mathrm{ABC}$ groups to form eight groups consisting of three teams each. The configuration is shown in Figure 1.

Figure 1. The collaboration structure of teams and tri-campus groups

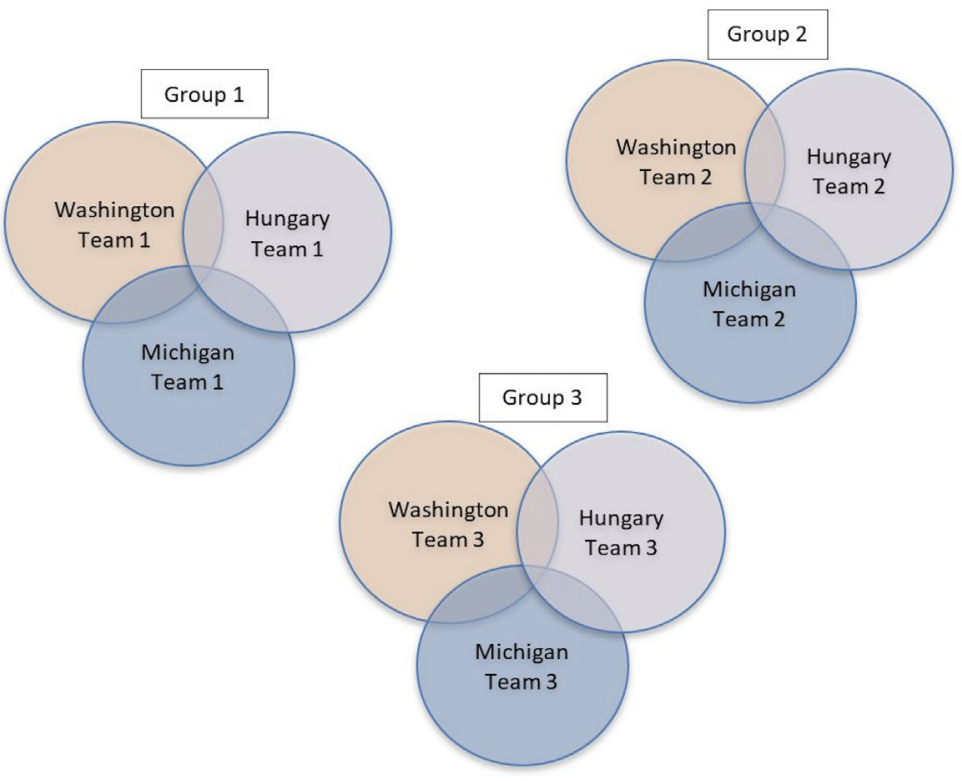


Each group's main goal was to produce two tangible products: a business plan and a website. All groups also engaged in several substantive technical and professional communication-focused learning and practice activities to provide advice, technical know-how, and feedback to each other within their client-provider relationships. Washington teams - which consisted of technical communication undergraduates serving as consultants - also had the role of inducting their undergraduate peer groups in Hungary and Michigan into disability theory and accessible design principles in the initial stages of the project. In addition, the Washington teams also learned to develop reports and proposal documents with their instructor to communicate their disability and accessibility knowhow to the other two teams. Thus, each of the Hungarian teams developed a business plan and the Michigan teams designed and built websites for each of these proposed businesses; the accessibility advice offered by each of the Washington groups primarily supported the work of other two teams in designing disabled-friendly accessible business venues and websites, while learning general technical communication genres and skills. Figure 2 illustrates the project deliverables and working relationships among the three teams.

Figure 2. Project deliverables and communication routes among the three teams

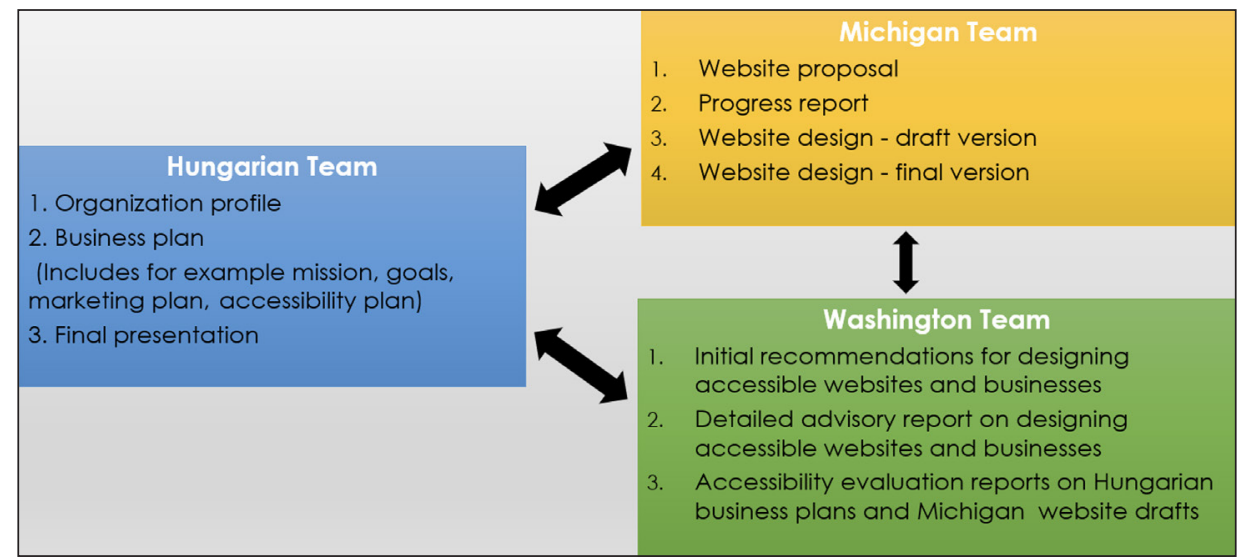

As Figure 2 shows, student teams at each university were responsible for their own deliverables (listed under each team) while they received input from the other two teams in their group to complete these deliverables. For example, a student team in Hungary worked on their business plan and included advice from their Washington partner team to make the business more accessible. At the same time, a student team in Michigan used input from its Hungarian partner team about the website content for the proposed business while also relying on advice from its Washington partner team on how to make these websites more accessible. The Washington teams based their website accessibility advice on the World Wide Web Consortium's (2008) Web Content Accessibility 
Guidelines 2.0 and shared readings, such as Oswal (2014, 2018) and Theofanos and Redish (2003) about the principles of website accessibility. While the project did not involve collaborating on the production of one single artifact across institutions and countries, students at the three different locations did work together as interlinked teams (groups of teams) across the three institutions, providing feedback and critique, and supporting one another's projects as they produced the required deliverables.

On the teaching end, the design of the individual assignments in the three courses, as well as integration of learning about disability and accessibility, required close collaboration among the three instructors. This collaboration resulted in each instructor modifying the emphasis areas of the assignments of their discipline. For example, teaching how to conceptualize European business plans that are inclusive of disabled users, customers, and workers from the ground up; including instruction on website design with a focus on accessibility in a professional writing course; and expanding a gateway course on technical communication to include more advanced-level assignments on the accessibility of the built environment and of websites. Instructors also had to place special emphasis on explicitly teaching successful communication strategies across disciplines and national boundaries to clarify the culturally diverse values of disability inclusion and access. Thus, the functional purpose of this collaboration project emerged as creating business models that are inclusive of marginalized populations and designing accessible websites usable by all.

While such collaboration could be possible among different courses at one university, by exposing students to the views about disability and accessibility from different cultures, this project highlighted that disability has different connotations in different cultures and the motivation to accommodate disabilities also differs across cultures. The exchange of ideas and perspectives and the shared experiences among the student groups were further strengthened by the interdisciplinary nature of this project. The interlinked curricula of three courses from three disciplines in two countries influenced the formulation and structure of the assignments due to the mingling of assignment designs, teaching pedagogies, and the shared instructional strategies adopted by the instructors to ensure an overall focus on accessibility. The products of two of the classes - the business plans and related websites - were collaboratively developed by the three teams, which naturally integrates the typical characteristics of partitioned teamwork within companies.

\section{Key questions for this research inquiry}

This long-term pedagogical collaboration is based on four research questions which focus on determining the effectiveness of the project design. The basic structure of our project remains 
roughly the same from year to year; however, we make design changes in response to student and instructor feedback and based on the outcomes in an effort to iterate on the effectiveness of our pedagogy. The primary changes in the second year of this project consisted of

- the addition of an introductory meeting via video conference among teams;

- the use of the Moodle platform as a shared space for each group to communicate and post their work (which was previously done via email);

- the inclusion of an icebreaker at the beginning of the project; and

- learning to prepare an agenda and take minutes at their group meetings.

To study the effectiveness of this modified project design, as well as the overall effectiveness of our teaching collaboration, we again focused on the same aspects of our project and employed our original three questions from the first year. For our qualitative data analysis, we added a fourth question that helps us understand and explain the effectiveness of the modifications to the project design. Thus, our research questions were as follows.

- What effects does the project design have on students' reported understanding of the significance of accessibility in web design and business planning?

- How effective is this pedagogical approach for teaching students about accessible business planning, developing equitable business practices, and providing customers with accessible websites?

- What kind of benefits does this type of disability and accessibility instruction have on the overall learning environment?

- Did students' perception of learning shift with the modifications in project design?

\section{Methods}

Because this is a multi-year study, we have attempted to keep our research methods for this iteration comparable to the previous one. The research described here is based on the second iteration of this three-way collaboration project during which we made four modifications to the project design. However, the overall structure of the project remained the same.

The first and most significant change was the addition of the Moodle learning management system to replace the total dependence on email for exchanging information and drafts of various documents among the groups. We decided to replace emails with Moodle as the main form of communication among teams because students often forgot to copy the instructors in their emails during the first 
year, which made the management of the collaboration process challenging. The instructors not being in the loop in some of these email threads made assessment of group work also problematic.

Second, we also added new activities near the beginning of this project. The three-team groups participated in an icebreaker in order to develop social interactions among the members. Third, students organized and attended one video conference as a group to introduce themselves to one another and to share their understanding of the logistics of the collaboration. The video meeting also gave an opportunity to Hungarian students to practice their language skills with native English language speakers in Michigan and Washington, something encouraged in language learning literature (Jauregi, De Graaff, Van den Bergh, \& Kriz, 2012). Fourth, we used the preparation for this introductory video meeting as an opportunity to model the use of a meeting agenda for our students. We thus added two minor writing assignments that were attached to these meetings: developing an agenda and taking minutes. Beyond the four changes that affected all of the students, the instructors of the Washington and Michigan students also added readings about accessibility in this second iteration because they wanted their students to learn about web accessibility through reading of these materials rather than just depending only on their instructors' lectures.

Another significant variation from the first iteration of this project to the second was in the courses that took part in the international collaboration. Due to changes in the instructors' teaching schedules we were unable to maintain the same course/disciplines that were present in Year 1. Table 1 below shows the courses that participated in the project in Year 1 and Year 2.

Table 1. Year 1 and Year 2 participating courses

\begin{tabular}{|l|l|l|}
\hline Participating university locations & Year 1 & \multicolumn{2}{l|}{ Year 2 } \\
\hline Hungary & \multicolumn{2}{|l|}{} \\
\hline Course title & English for Business & English for Business \\
\hline Student level & Undergraduate & Undergraduate \\
\hline Number of students & 31 & 33 \\
\hline Michigan & \multicolumn{2}{|l|}{} \\
\hline Course title & Business Communication & Intro to Professional Writing \\
\hline Student level & Undergraduate & Undergraduate \\
\hline Number of students & 21 & 24 \\
\hline Washington & \multicolumn{2}{|l|}{} \\
\hline Course title & Disability Theory & Technical Communication \\
\hline Student level & Graduate & Undergraduate \\
\hline Number of students & 10 & 25 \\
\hline
\end{tabular}


In accordance with the first iteration, we also used a mixed method research protocol in this second-year study where we collected and analyzed qualitative and quantitative data (see Palmer et al., 2020 for the first-year data). This data analysis approach helps to uncover emerging themes that are important to observe when students are initially introduced to concepts connected to disability and accessibility, a differentiating feature of our international collaboration pedagogy. Researchers involved in disability-related mixed method studies have further concluded that quantitative and qualitative approaches can complement each other when used in tandem. O'Day and Killeen (2002) further explain that "their integration can create a valuable lens through which to analyze the complexity of the disability experience and to measure the progress toward the goal of the full integration of persons with disabilities into society” (p. 9). Since the purpose of the disability and accessibility component of our curriculum is to integrate the usability experiences of disabled clients and users in our students' entrepreneurial businesses and their websites, the mixed methods approach allows us to collect not only quantitative data about students' selfreported learning, but also to capture qualitative data that adds color and nuance to the numerical data.

More specifically, our research method can be identified as "explanatory sequential design" (Creswell, 2015, p. 37). In this approach, a quantitative survey is expanded with open-ended questions and additional qualitative data is also gathered with the goal of explaining and describing the phenomena observed by the researchers. Overwhelmingly, we depend on data gathered through the survey questions about student perceptions to reflect on our overall effectiveness of our collaboration. Our study design does not have a typical validation mechanism because of its focus on describing and explaining the data - particularly the qualitative data from our students and our perceptions of the pedagogical choices we made during these two years. In this aspect, our study has been designed like a qualitative project that also gathers and presents quantitative data about students' perceptions. Results are then reported in an aggregate manner where quantitative findings are supported with evidence from the qualitative dataset, partially for the purpose of comparison between the quantitative and qualitative data to add to the rigor of the study. Additional results to our fourth research question are then further explained in the final discussion section relying on qualitative data from our surveys and student interactions as well as from our teaching notes. The mixed methods research design also allows additional insights into the findings that cannot be otherwise gained from purely quantitative data. This is especially important for an interdisciplinary collaboration such as ours where the project design aims to incorporate curricula and pedagogies from different disciplines while giving each student group an opportunity to gain the experience of working in client-provider relationships with groups from the other two universities. Scholars in virtual exchange field have also made a case for a mixed methods approach because it widens the scope for collecting data to portray the 
impact of collaboration across-the-board and assists in covering the interdisciplinary aspects of technological and content knowledge (Hauck, Müller-Hartmann, Rienties, \& Rogaten, 2020).

\subsection{Data collection}

A pre- and post-project survey was used to gather data from students at all locations. The three instructors collaborating on this project formulated questions for these surveys. The pre-project survey focused on students' previous knowledge and preconceived notions regarding disability, and their overall cultural attitudes toward accessibility. The post-project survey repeated the same questions in order to assess if any of these knowledge areas or attitudes changed as a result of students' participation in the collaboration project, the effect of the shared curriculum and activities about disability and accessibility, and the emphasis of our pedagogy on diversity and inclusion. The post-project survey also included additional open-ended questions that asked students to report on their experiences. Finally, student messages from their Moodle groups and transcripts of recorded video meeting minutes were also analyzed using qualitative methods. The findings from the analyses of these two qualitative data pools were triangulated with the quantitative survey data. We supplemented this mixed data pool with the teaching notes from the three instructors when this qualitative data was helpful in completing the picture of one or the other aspects of this collaboration, or was pertinent for explaining a datum from other sources. In our discussion of these results, we at times also cross-referenced student feedback that we received in our respective classes.

\subsection{Survey participants}

A total of 82 students were enrolled in the three courses that participated in this online collaboration project - 33 students in the Hungarian class, 24 students in the Michigan class, and 25 students in the Washington class. All students were asked to complete the survey. The survey was hosted on a free online survey platform which collected responses anonymously while identifying the students' campus and group number. After forming the groups, instructors asked students to fill out the preproject survey. The post-project survey was then completed once the project was over. All three university courses were equally represented in both surveys.

\subsection{Description of the quantitative data and analysis}

The pre-project survey included 15 questions consisting of multiple choice, frequency, and openended questions. The three instructors developed the survey questions with their curriculum content and collaboration design in mind. These questions focused on students' knowledge about the business culture of the other participants' countries, business planning, website design, and 
disability and accessibility. The same 15 questions were repeated on the post-project survey in past tense and with additional questions that related to students' experiences with the project. The data analysis presented here focuses only on a subset of these 15 questions that are directly related to our main research questions (for a detailed list of all research questions, see Appendix A in Palmer et al., 2020). The additional questions probed students' perceptions about the effectiveness of this project with teaching business communication, intercultural communication, and accessibility know-how. Finally, students were also asked to rate the success of their own campus team as well as their tri-campus group. Survey results were analyzed using SPSS 25.0 for Windows. Frequencies and descriptive statistics were used to report and interpret data. Note that because the choice regarding whether or not to participate in the pre- and post-surveys was left to the students, the totals do not match (61 responses for the pre-project survey and 70 for the post-project survey). Thus, in the data analysis we relied on percentages rather than on the raw numbers.

\subsection{Description of the qualitative data and analysis}

Student messages from the Moodle discussion boards of the eight project groups were collected for analysis and were combined with the data collecte $d$ through the open-ended survey questions. Because the students took the two surveys anonymously, we could not separate out non-survey qualitative data for those students who might not have completed the pre- or post-survey. The textual data was assigned to specific project phases and was coded based on its purpose. These codes were compared among the eight groups and themes were developed that were present in all the group discussions. The themes focused on how to improve the accessibility of the proposed business and websites, and what content and visuals to incorporate into the website. These themes were comparable to the themes listed in the first-year study. The themes were triangulated with all additional data gathered. Triangulation consists of at least two research techniques of data collection to tackle the same research question (Morse, 1991). Working within the qualitative paradigm, we did not apply triangulation as a tool for validating our data but rather in order to deepen and enrich our analysis (Flick, 1998, p. 230). In the words of Greene, Caracelli, and Graham (1989), triangulation can be employed for results acquired from more than one technique to "measure overlapping, but different facets of a phenomenon, yielding an enriched, elaborated understanding of that phenomenon” (pp. 258-259).

\section{Results}

Our study sought to answer four research questions: (1) the effects of the project design on students' intersectional understanding of the concept of accessibility in web design and business planning, (2) 
the effectiveness of our pedagogical approach for teaching how to apply accessible design principles to business planning and web design, (3) the benefits of this instruction on the overall learning environment, and (4) students' perception of learning with the four modifications to the project design. The findings are presented in the order of the research questions.

\subsection{RQ1. Students' understanding of the concept of accessibility}

In the pre-project survey, one question asked students to mark what type of knowledge and skills they expected to gain during the project, while in the post-project survey they were asked to mark what knowledge and skills they thought they had actually developed through this collaboration, as well as the learning they acquired from their instructors. The findings reveal that there was a shift from what the students expected to learn before the project and what they perceived they had learned after the project. Table 2 shows the pre-project expectations of the Hungarian students and their post-project perceptions related to skills and knowledge gained. Before the project start, a portion of the Hungarian students ( $n=6,30 \%$ ) expected to improve foreign language skills (a). In addition to foreign language skills, other skills and knowledge Hungarian students expected to learn include: practical communication skills across cultures (b) $(n=10,50 \%)$, improved knowledge about intercultural communication principles (c) $(n=4,20 \%)$, improved understanding of the business culture of the partner team's county (d) $(n=9,45 \%)$, improved knowledge about business planning and business operation (e) ( $n=13,65 \%)$, and improved knowledge about effective website content and organization (f) ( $n=2,10 \%)$. None of the Hungarian students expected to gain improved knowledge about website accessibility $(\mathrm{g})(n=0)$ before the project.

The post-project survey asked students to report the skills and knowledge they perceived they have gained during the project. The results on this post-project survey for Hungarian students show knowledge and skills in the following categories: improved foreign language skills (a) ( $n=8$, $30 \%)$, practical communication skills across cultures (b) ( $n=13,48 \%)$, improved knowledge about intercultural communication principles (c) $(n=8,30 \%)$, improved understanding of the business culture of the partner team's county (d) (n=6, 22\%), improved knowledge about business planning and business operation (e) ( $n=16,59 \%)$, and improved knowledge about effective website content and organization (f) $(n=4,15 \%)$. Although none of the Hungarian students expected to learn about website accessibility (g) in the pre-project survey, after the project, $44 \%(n=12)$ of them felt they gained improved knowledge in this area. Improved knowledge about website accessibility (g) was the area where the largest increase could be observed in self-reported learning. While the number of students taking the survey was not equal at each time - as noted earlier - improved understanding of the business culture of the partner team's country (d) was an area with the most relevant decrease between pre-( $n=9,45 \%)$ and post-project $(n=6,22 \%)$ numbers. 
Table 2. Hungarian students' pre-project expectations and post-project perceptions related to skills and knowledge gain

\begin{tabular}{|c|c|c|c|c|c|}
\hline \multirow{2}{*}{\multicolumn{2}{|c|}{\begin{tabular}{|l|} 
Skills and knowledge \\
Hungarian students $(\mathrm{n}=20 / 27)$ \\
\end{tabular}}} & \multicolumn{2}{|c|}{$\begin{array}{l}\text { Pre-project } \\
\text { survey }\end{array}$} & \multicolumn{2}{|c|}{$\begin{array}{l}\text { Post-project } \\
\text { survey }\end{array}$} \\
\hline & & \multirow{2}{*}{$\begin{array}{l}\text { f } \\
6 \\
\end{array}$} & \multirow{2}{*}{$\begin{array}{l}\mathbf{f} / \mathbf{n}(\%) \\
30\end{array}$} & \multirow{2}{*}{$\begin{array}{l}\text { f } \\
8\end{array}$} & \multirow{2}{*}{$\begin{array}{l}\mathbf{f} / \mathbf{n}(\%) \\
30\end{array}$} \\
\hline a & Improved foreign language skills & & & & \\
\hline $\mathrm{b}$ & Improved practical communication skills across cultures & 10 & 50 & 13 & 48 \\
\hline c & Improved knowledge about intercultural communication principles & 4 & 20 & 8 & 30 \\
\hline$d$ & Improved understanding of the business culture of the partner team's country & 9 & 45 & 6 & 22 \\
\hline e & Improved knowledge about business planning, business operation & 13 & 65 & 16 & 59 \\
\hline $\mathrm{f}$ & Improved knowledge about effective website content and organization & 2 & 10 & 4 & 15 \\
\hline g & Improved knowledge about website accessibility & 0 & 0 & 12 & 44 \\
\hline $\mathrm{h}$ & Other & 0 & 0 & 0 & 0 \\
\hline
\end{tabular}

The same data for Michigan students is summarized in Table 3. As we can see in Table 3, none of the Michigan students have expected to gain foreign language skills (a) since the contact language of the project was English. The skills and knowledge Michigan students expected to learn include: practical communication skills across cultures (b) ( $n=16,76 \%)$, improved knowledge about intercultural communication principles (c) $(n=10,47 \%)$, improved understanding of the business culture of the partner team's country (d) ( $n=11,52 \%)$, improved knowledge about business planning and business operation (e) ( $n=7,33 \%)$, improved knowledge about effective website content and organization (f) ( $n=10,47 \%)$, and improved knowledge about website accessibility (g) ( $n=4,19 \%)$ before the project.

In sum, the post-project survey asked students to report the skills and knowledge they perceived they have gained during the project. The results from this post-project survey for Michigan students show changes in knowledge and skills in the following categories: improved foreign language skills (a) ( $n=0,0 \%)$, practical communication skills across cultures (b) $(n=12,52 \%)$, improved knowledge about intercultural communication principles (c) $(n=3,13 \%)$, improved understanding of the business culture of the partner team's country (d) $(n=3,13 \%)$, improved knowledge about business planning and business operation (e) ( $n=16,70 \%)$, improved knowledge about effective website content and organization (f) ( $n=17,74 \%$ ), and improved knowledge about website accessibility (g) ( $n=18,78 \%$ ). Similar to the Hungarian students, for the Michigan students it was the improved knowledge about website accessibility (g) where the largest increase could be observed in self-reported learning. Large increases between pre- and post-project values can also be seen in the categories of improved knowledge about business planning (e) - an important topic of interaction with the Hungarian team, and improved knowledge about effective website content and organization (f) - the focus of class instruction in Michigan during the project. The most noticeable decreases in perceived learning for 
the Michigan group connected to intercultural communication principles (c), and the partner team's business culture (d).

\section{Table 3. Michigan students' pre-project expectations and post-project perceptions related to skills and knowledge gain}

\begin{tabular}{|c|c|c|c|c|c|}
\hline \multirow{2}{*}{\multicolumn{2}{|c|}{\begin{tabular}{|l} 
Skills and knowledge \\
Michigan students (n=21/23) \\
\end{tabular}}} & \multicolumn{2}{|c|}{$\begin{array}{l}\text { Pre-project } \\
\text { survey }\end{array}$} & \multicolumn{2}{|c|}{$\begin{array}{l}\text { Post-project } \\
\text { survey }\end{array}$} \\
\hline & & \multirow{2}{*}{$\begin{array}{l}\mathbf{f} \\
0\end{array}$} & \multirow{2}{*}{$\begin{array}{l}\mathbf{f} / \mathbf{n}(\%) \\
0\end{array}$} & \multirow{2}{*}{$\begin{array}{l}\mathbf{f} \\
0\end{array}$} & \multirow{2}{*}{$\begin{array}{l}\mathbf{f} / \mathbf{n}(\%) \\
0\end{array}$} \\
\hline a & Improved foreign language skills & & & & \\
\hline $\mathrm{b}$ & Improved practical communication skills across cultures & 16 & 76 & 12 & 52 \\
\hline C & Improved knowledge about intercultural communication principles & 10 & 47 & 3 & 13 \\
\hline $\mathrm{d}$ & Improved understanding of the business culture of the partner team's country & 11 & 52 & 3 & 13 \\
\hline $\mathrm{e}$ & Improved knowledge about business planning, business operation & 7 & 33 & 16 & 70 \\
\hline f & Improved knowledge about effective website content and organization & 10 & 47 & 17 & 74 \\
\hline $\mathrm{g}$ & Improved knowledge about website accessibility & 4 & 19 & 18 & 78 \\
\hline $\mathrm{h}$ & Other & 0 & 0 & 0 & 0 \\
\hline
\end{tabular}

Table 4 below reveals the Washington students replies on pre- and post-project surveys with regards to skills and knowledge gained. While some Washington students did expect to gain foreign language skills (a) $(n=3,15 \%)$, the post-project survey shows that none of them did gain these skills ( $n=0,0 \%$ ) which can be explained by the fact that the contact language of the project was English, also used as the language of instruction in Washington. Other skills and knowledge Washington students expected to learn as indicated on the pre-project survey include: practical communication skills across cultures (b) ( $n=11,55 \%)$, improved knowledge about intercultural communication principles (c) ( $n=11,55 \%)$, improved understanding of the business culture of the partner team's country (d) ( $n=8,40 \%)$, improved knowledge about business planning and business operation (e) ( $n=7,35 \%)$, improved knowledge about effective website content and organization (f) ( $n=11,55 \%)$, and improved knowledge about website accessibility $(\mathrm{g})(n=4,20 \%)$ before the project. In addition, one Washington student indicated to gain other (h) $(n=1,5 \%)$, non-specified, skills from the project.

On the post-project survey, Washington students also indicated skills and knowledge gained in the following categories: practical communication skills across cultures (b) $(n=10,50 \%)$, improved knowledge about intercultural communication principles (c) $(n=6,30 \%)$, improved understanding of the business culture of the partner team's country (d) $(n=1,5 \%)$, improved knowledge about business planning and business operation (e) ( $n=2,10 \%)$, improved knowledge about effective website content and organization (f) ( $n=12,60 \%)$, and improved knowledge about website accessibility (g) $(n=11,55 \%)$. Four Washington students also indicated they have gained other $(\mathrm{h})(n=4,20 \%)$, non- 
specified skills, during the project. As with the other two groups, the largest increase between preproject expectations and post-project reporting is in the improved skills about website accessibility (g) category as reported by the Washington students. The most relevant decreases between expected skills and knowledge reported on the pre-project survey and the post-project survey result are in categories of understanding the business culture of the partner team's country (d) and knowledge about business planning and business organization (e).

Table 4. Washington students' pre-project expectations and post-project perceptions related to skills and knowledge gain

\begin{tabular}{|c|c|c|c|c|c|}
\hline \multirow{2}{*}{\multicolumn{2}{|c|}{$\begin{array}{l}\text { Skills and knowledge } \\
\text { Washington students (n=20/20) }\end{array}$}} & \multicolumn{2}{|c|}{$\begin{array}{l}\text { Pre-project } \\
\text { survey }\end{array}$} & \multicolumn{2}{|c|}{$\begin{array}{l}\text { Post-project } \\
\text { survey }\end{array}$} \\
\hline & & \multirow{2}{*}{\begin{tabular}{|l|} 
f \\
3
\end{tabular}} & \multirow{2}{*}{$\begin{array}{l}\mathbf{f} / \mathbf{n}(\%) \\
15\end{array}$} & \multirow{2}{*}{\begin{tabular}{|l} 
f \\
0
\end{tabular}} & \multirow{2}{*}{$\begin{array}{l}\mathbf{f} / \mathbf{n}(\%) \\
0\end{array}$} \\
\hline a & Improved foreign language skills & & & & \\
\hline $\mathrm{b}$ & Improved practical communication skills across cultures & 11 & 55 & 10 & 50 \\
\hline c & Improved knowledge about intercultural communication principles & 11 & 55 & 6 & 30 \\
\hline d & Improved understanding of the business culture of the partner team's country & 8 & 40 & 1 & 5 \\
\hline e & Improved knowledge about business planning, business operation & 7 & 35 & 2 & 10 \\
\hline $\mathrm{f}$ & Improved knowledge about effective website content and organization & 11 & 55 & 12 & 60 \\
\hline $\mathrm{g}$ & Improved knowledge about website accessibility & 4 & 20 & 11 & 55 \\
\hline $\mathrm{h}$ & Other & 1 & 5 & 4 & 20 \\
\hline
\end{tabular}

The summary of the data from all three groups (see Table 5) reveals an overall shift from what the students expected before the project and what they perceived they learned after the project. For example, before the project began, 37 students expected to acquire practical communication skills across cultures (b). In the post-project survey, 35 students reported that they did acquire these practical skills, which may be a slightly smaller number of students; however, we see these gains as significant. The overall percentage of students interested in these gains both at the beginning and end of the collaboration might also have been affected by the specific focus of each of the courses and by the overarching focus on accessibility and disability.

Learning about website accessibility ( $\mathrm{g}$ ) as an expectation was ranked the lowest among student expectations $(13 \%, n=8)$ on the pre-project survey. After the project, however, students felt their knowledge about website accessibility increased the most to $59 \%(n=41)$, signaling a $46 \%$ rise. In the case of website content and organization (f), 47\% ( $n=33)$ of the students perceived to have improved. Business planning (e) came next, with $49 \%$ of the students $(n=34)$ claiming to have improved knowledge by the end of the project, which marks a 5\% increase. On the other hand, two categories of learning have shown notable decreases across all students' answers when we compare pre- and 
post-project data. One of this is learning about intercultural communication principles (c) and the other is learning about the business culture of the partner team's country $(d)$.

\section{Table 5. Summary comparison of all students' pre-project expectations and post-project perceptions related to skills and knowledge gain}

\begin{tabular}{|c|c|c|c|c|c|}
\hline \multirow{2}{*}{\multicolumn{2}{|c|}{\begin{tabular}{|l|} 
Skills and knowledge \\
Students $(\mathrm{N}=61 / 70)$ \\
\end{tabular}}} & \multicolumn{2}{|c|}{$\begin{array}{l}\text { Pre-project } \\
\text { survey }\end{array}$} & \multicolumn{2}{|c|}{$\begin{array}{l}\text { Post-project } \\
\text { survey }\end{array}$} \\
\hline & & \multirow{2}{*}{$\begin{array}{l}\text { f } \\
9\end{array}$} & \multirow{2}{*}{$\begin{array}{l}\mathbf{f} / \mathbf{n}(\%) \\
15 \\
\end{array}$} & \multirow{2}{*}{$\begin{array}{l}\mathbf{f} \\
8\end{array}$} & \multirow{2}{*}{\begin{tabular}{|l}
$\mathbf{f} / \mathbf{n}(\%)$ \\
11 \\
\end{tabular}} \\
\hline a & Improved foreign language skills & & & & \\
\hline $\mathrm{b}$ & Improved practical communication skills across cultures & 37 & 61 & 35 & 50 \\
\hline c & Improved knowledge about intercultural communication principles & 25 & 41 & 17 & 24 \\
\hline $\mathrm{d}$ & Improved understanding of the business culture of the partner team's country & 28 & 46 & 10 & 14 \\
\hline e & Improved knowledge about business planning, business operation & 27 & 44 & 34 & 49 \\
\hline f & Improved knowledge about effective website content and organization & 23 & 38 & 33 & 47 \\
\hline g & Improved knowledge about website accessibility & 8 & 13 & 41 & 59 \\
\hline $\mathrm{h}$ & Other & 1 & 2 & 4 & 6 \\
\hline
\end{tabular}

Similar patterns were observed in the Year 1 dataset (see Table 6). In Year 1, 19\% $(n=10)$ of the students expected to gain knowledge about website accessibility (g), while $47 \%$ ( $n=22$ ) of the students claimed to have acquired considerable knowledge about website accessibility by the end of the project - an increase of 28 percentage points. In Year 2, only 13\% of students expected to gain knowledge about website accessibility at the beginning of the project but this rose by 46 percentage points to $59 \%$ of the students by the end of the project. The second year of results also illustrate that students did show gains in their knowledge about website accessibility, which may indicate that accessibility instruction in the interdisciplinary setting can have an effect on students' self-reported understanding of accessibility concepts.

The analysis of students' forum posts in Moodle revealed that their social sensitivity and openness to disability increased. They seem to have understood the importance of accessibility regardless of their disciplines and key focus of their studies, and expressed their positive attitudes toward accessible solutions for the website and business procedures of their start-up companies. When discussing solutions to designing accessible businesses, one of the Hungarian teams realized that they needed to make their businesses "enjoyable for everybody and help people with any kind of disability" (Hungarian team \#3). Based on the communication between the Hungarian and Michigan teams, it became clear that the Michigan groups regarded accessibility as the key goal for their projects and followed all the guidelines of the Washington students (who had the role of accessibility advisor/consultant) in reaching their goals. As one of the Washington student teams advised, "the 
accessibility and usability of the website for disabled users is an important issue that should not be ignored or addressed as a last-minute burden on the business" (Washington team \#4). The following Moodle post summarizes students' attitude toward accessibility: "we have a civil, moral, and professional responsibility to serve everyone and make sure they [the disabled users] have the same opportunities regarding our business and its website” (Michigan team \#1).

Table 6. Year 1 and Year 2 comparison of students' pre-project expectations and post-project perceptions related to skills and knowledge gain

\begin{tabular}{|c|c|c|c|c|c|c|c|c|c|}
\hline \multirow{3}{*}{\multicolumn{2}{|c|}{$\begin{array}{l}\text { Skills and knowledge } \\
\text { Students (Ny1=52/47), (Ny2=61/70) }\end{array}$}} & \multicolumn{4}{|c|}{ Year 1} & \multicolumn{4}{|c|}{ Year 2} \\
\hline & & \multicolumn{2}{|c|}{ Pre-project } & \multicolumn{2}{|c|}{ Post-project } & \multicolumn{2}{|c|}{ Pre-project } & \multicolumn{2}{|c|}{ Post-project } \\
\hline & & f & f/n (\%) & f & f/n (\%) & f & f/n (\%) & f & f/n (\%) \\
\hline a & Foreign language skills & 13 & 25 & 12 & 25 & 9 & 15 & 8 & 11 \\
\hline $\mathrm{b}$ & Practical communication skills across cultures & 34 & 65 & 26 & 55 & 37 & 61 & 35 & 50 \\
\hline c & Intercultural communication principles & 27 & 52 & 13 & 28 & 25 & 41 & 17 & 24 \\
\hline $\mathrm{d}$ & Business culture of the partner team's country & 13 & 25 & 5 & 11 & 28 & 46 & 10 & 14 \\
\hline e & Business planning, business operation & 25 & 48 & 25 & 53 & 27 & 44 & 34 & 49 \\
\hline $\mathrm{f}$ & Effective website content and organization & 14 & 27 & 19 & 40 & 23 & 38 & 33 & 47 \\
\hline $\mathrm{g}$ & Website accessibility & 10 & 19 & 22 & 47 & 8 & 13 & 41 & 59 \\
\hline $\mathrm{h}$ & Other & 0 & 0 & 0 & 0 & 1 & 2 & 4 & 6 \\
\hline
\end{tabular}

\subsection{RQ2. Effectiveness of the pedagogical approach for teaching how to apply accessible design principles in business planning and web design}

Students rated the project effectiveness on a seven-point scale (see Table 7) and 70\% of the respondents gave marks of five or higher, which indicates that students found that the project was indeed effective in teaching about accessibility concepts and solutions $(M=5.37, S D=1.72)$. The mean value was the highest among the Michigan students $(M=6, S D=1.16)$, while the two other groups rated the project effectiveness in this respect slightly lower.

\section{Table 7. Project's overall effectiveness in informing about accessibility}

\begin{tabular}{|l|l|l|}
\hline Project effectiveness in informing about accessibility & Mean & SD \\
\hline All respondents $(\mathrm{N}=70)$ & 5.37 & 1.72 \\
\hline Hungarian groups $(\mathrm{n}=27)$ & 5.04 & 1.53 \\
\hline Michigan groups $(\mathrm{n}=23)$ & 6.00 & 1.16 \\
\hline Washington groups $(\mathrm{n}=20)$ & 5.10 & 2.29 \\
\hline
\end{tabular}


If we compare these results with the previous year's data (see Table 8), the overall effectiveness of the project was rated higher in the case of Hungarian students and Michigan students, while students in Washington gave this iteration a lower rating.

Table 8. Year 1 and Year 2 comparison of overall effectiveness in informing about accessibility

\begin{tabular}{|l|l|l|l|l|}
\hline \multirow{2}{*}{ Project effectiveness in informing about accessibility } & \multicolumn{3}{|l|}{ Year 1 } & Year \\
\cline { 2 - 5 } & Mean & SD & Mean & SD \\
\hline All respondents (Ny1=47; Ny2=70) & 5.00 & 1.53 & 5.37 & 1.72 \\
\hline Hungarian groups (ny1=21; ny2=27) & 4.33 & 1.49 & 5.04 & 1.53 \\
\hline Michigan groups (ny1=17; ny2=23) & 5.53 & 1.12 & 6.00 & 1.16 \\
\hline Washington groups (ny1=9; ny2=20) & 5.56 & 1.60 & 5.10 & 2.29 \\
\hline
\end{tabular}

The video meeting discussions among the tri-campus groups and messages on Moodle also show that students paid more attention to the application of accessibility principles as the project progressed. The following quotation from a discussion forum post in one of the Moodle groups attests to the changes this team planned to undertake to make their business more accessible:

"we can make changes to make our tours accessible for physically disabled people as many of the programs included in the packages require physical activity (e.g. horse ranch). We agreed to review the packages and include hotels and other accommodations that are accessible and use vehicles (buses) with low floor[s]” (Hungarian team \#2).

They even mentioned, "we would like to hire people with disabilities to our office" (Hungarian team \#2).

In one of the initial meetings, a Michigan team was already considering some accessibility features of their website as they relate to the site's visual design which is illustrated by the following guidelines laid out in their video meeting minutes: "website: not too colorful (obsessive compulsive disorder, color blind people)" (Michigan team \#7). Another Michigan team (\#8) in their meeting minutes mentioned the attention that needs to be paid to the website's headings for accessibility reasons.

\subsection{RQ3. Benefits of instruction on the overall learning environment}

Two of the survey questions specifically addressed detailed knowledge about business planning and website design. Results of pre- and post-project surveys on these questions show that the students 
perceived that their knowledge of business planning and accessible website design improved due to the project. Before the project, $67 \%(n=41)$ of the students said that they did not have any previous experience in business planning (see Table 9), and 46\% ( $n=28)$ did not have experience in website design (see Table 10). After the project, these percentages went down to $4 \%(n=3)$ in the case of business planning and 26\% ( $n=18)$ website design, indicating that students felt that they gained knowledge in both of these areas.

\section{Table 9. Students' pre-project knowledge and post-project perceptions of business planning ${ }^{*}$}

\begin{tabular}{|l|l|l|l|l|l|}
\hline \multicolumn{2}{|l|}{ Business planning } & \multicolumn{3}{l|}{ Pre-project survey } & \multicolumn{2}{l|}{ Post-project survey } \\
\hline \multicolumn{2}{|l|}{ Students (N=61/70) } & f & f/n (\%) & f & f/n (\%) \\
\hline a & I know a lot about entrepreneurship and starting a business & 2 & 3 & 18 & 26 \\
\hline b & I have some idea about entrepreneurship and business planning & 7 & 11 & 33 & 47 \\
\hline c & I have just a little idea about business planning & 13 & 21 & 16 & 23 \\
\hline d & Business planning is a completely new field for me & 41 & 67 & 3 & 4 \\
\hline
\end{tabular}

*Note: respondents could choose more than one answer. Hence the total of the responses does not match the participant $\mathrm{N}$ pre and post.

\section{Table 10. Students' pre-project knowledge and post-project perceptions of website design*}

\begin{tabular}{|l|l|l|l|l|l|}
\hline \multicolumn{2}{|l|}{ Website design } & Pre-project survey & \multicolumn{2}{l|}{ Post-project survey } \\
\hline Students (N=61/70) & f & f/n (\%) & f & f/n (\%) \\
\hline a & I built my own website using ----- software & 3 & 5 & 11 & 16 \\
\hline b & I know HTML and can code web pages & 7 & 11 & 6 & 9 \\
\hline c & I worked on a collaborative website design project & 8 & 13 & 33 & 47 \\
\hline d & I created content for a website & 12 & 20 & 27 & 39 \\
\hline e & I used ready-made templates available free on the internet to create websites & 23 & 38 & 29 & 41 \\
\hline f & None of the above & 28 & 46 & 18 & 26 \\
\hline
\end{tabular}

*Note: respondents could choose more than one answer. Hence the total of the responses does not match the participant $\mathrm{N}$ pre and post.

By analyzing students' closing posts in Moodle, we can say that they appreciated the interdisciplinary element of this collaboration project and they felt that notions of accessibility gave them new lenses and new perspectives to approach their own projects. As one of the Hungarian students put it: "thank you for [...] a new aspect which concerns the people with disabilities" (Hungarian team \#1) and another student felt that it gave them a "new perception" in this regard (Hungarian team \#1). Students felt it broadened their horizons and started to consider accessible solutions in their own disciplines: "this collaborative project helped our group learn more about building a functional website and communicating with our peers in a different area (discipline) than ours" 
(Michigan team \#2). In addition, students mentioned the benefit of meeting their partner teams via video as the following quotation illustrates: "we greatly enjoyed the [...] videoconference. All of us emphasize that this is a good opportunity to experience how to work in a group, with people from different universities, from different time zones” (Hungarian Team \#3).

Students also highlighted the collaborative element of the project, where the teams were learning from each other and had to build on each other's expertise to be able to complete their tasks successfully. This peer-guided learning aspect of the project is reflected in the following two quotations from Michigan Team \#3: "your insight and knowledge about creating accessible websites came in handy for this project. The Michigan students learned a lot from your team". And "it was inspiring to know that we were creating a website that had the potential to actually be browsed by a visually impaired person. Your feedback pushed us in the right direction...”.

The Washington students openly expressed their positive thoughts about the overall benefits of the collaboration project: "it was a pleasure interacting and helping each other learn this quarter. [...] we all got a great experience out of this". And "I would like to thank both the Michigan and Hungarian teams for making this collaboration project an interesting and worthwhile experience. I will use the things I have learned for the rest of my education and future jobs”.

\subsection{RQ4. Students' perception of learning with the modifications in project design}

As stated in the methods section, we retained the survey questions from Year 1 for this study. However, as also explained above, we made some changes in the pedagogical set up to bring in additional affordances to support the international collaboration: Moodle, icebreakers, video meetings, and meeting agenda/minutes. Our choices in adding these technologies and assignments were guided by an awareness of what Hauck and Satar (2018) describe as, "a hierarchical and prescriptive use of technologies" that have "a tendency to reproduce power structures known from more traditional face-to-face classrooms” (p. 133). We wanted to engage technologies that would be available to all students, would have a short learning curve, and would support one of our pedagogical needs for students to develop a better social presence. The new technology additions also provided for multimodal interactions among students, something that was not possible in the email medium that is dependent primarily on text-based expression.

Our first change - the adoption of the Moodle platform for exchanging information - did not work as well as we had expected. Instructor notes suggest that none of the classes found Moodle to be user friendly and few students went beyond using it for posting drafts and essential messages. 
Some of this indifference to the dynamic features of Moodle might have been due to a learning curve that was steeper than we imagined it would be, as well as few students having familiarity with this platform. Michigan and Washington instructors found that while using Moodle was a great way to keep everything in one place, relying on discussion forums for communication made the interactions impersonal. Students treated messages as simply posts to a site, rather than as messages addressed to real people. Often, depending on how students adjusted their (email) notification preferences regarding activities happening in Moodle, messages were overlooked or ignored. In addition, it took some time for everyone to learn the use of the interface and they complained about this extra burden on top of the job of learning the website creation tool. And, they all have to use their own university's learning management systems - Blackboard and Canvas. Comparatively speaking, the email interactions during the first year worked quite well.

Our second change - the addition of an icebreaker to jumpstart the project - was popular among students because of its playful, quiz-like format in which we gave them an opportunity to share a local landmark and introduce themselves in connection with their location. Interactions around this icebreaker were, however, mostly structured around the description of the tourist attraction rather than anything related to the upcoming collaboration among the students. Not all students liked this particular icebreaker because they found it simplistic. If we use an icebreaker in the future, we would like to build some intellectual muscle into this assignment and tie it to the course project.

On the other hand, our employment of video conferencing as our third major change in this iteration proved meaningful. Social presence has been held responsible for establishing personal relationships in online learning settings and serves as "a catalyst for participation, community building, and collaboration” (Satar, 2020, p. 130). Although our survey did not seek student responses on the use of video conferencing, students' informal feedback indicated that it strengthened group bonds and students enjoyed the experience of seeing one another face-toface across distances. We plan to include video meetings in our future collaboration and will try to find ways to increase their utility for student collaboration within teams and groups. Recent research on video tools has underlined accessibility issues faced by disabled users and we plan to pay attention to the accessibility in the choice of a video tool in the future to be prepared for our students with disabilities (Hersh, Leporini, \& Buzzi, 2020; Leporini, Buzzi, \& Hersh, 2021).

As our fourth change, we introduced meeting agendas and minutes assignment in tandem with the video meeting. The introduction of these two elements exposed students to two new business writing genres, and we plan to add more instructional materials, such as sample documents for students to learn these genres on their own. 


\section{Interdisciplinary virtual exchange as a catalyst for pedagogical innovation}

Combining the seemingly disparate areas of disability awareness, business planning, and website design is clearly a differentiating characteristic of this project. The analyses of our data shows that students appreciated these innovative learning opportunities which also fall in line with emerging research on this topic (see for example Ullom, 2017). The motivation behind choosing the clientprovider model for our collaboration was to create realistic conditions for doing the class work and engaging students in hands-on learning activities. Our data exhibits how simulated client-provider relationships in an international collaboration among three groups of students from three different fields can help students acquire meaningful knowledge. Another advantage of the client-provider model was that it allowed adaptation of our respective in-country curricula.

As the analyses suggest, student data shifted in the positive direction about practical business communication skills and understanding of website accessibility from what they expected before the project and what they perceived they learned during this collaboration, although these improvements varied among the three campuses. This difference was expected since the project straddles students from three different subject areas and the knowledge gained largely came from the interdisciplinary focus of learning from other groups and the interdisciplinarity added by the three instructors in their assignments and pedagogy.

Students also registered acquisition of knowledge in discipline-specific assignments, even though their own class did not work on these areas outside of the collaborative learning activities among the tri-campus groups. For instance, before the project, most students did not know anything about business planning (67\%), whereas after the project only $4 \%$ students from the three classes recorded the lack of knowledge in this area. Likewise, students moved from knowing nothing about website design and building before the project toward knowing more after the project.

While the results about website accessibility learning are mixed among the various knowledge acquisition categories, some increase in this area was observed in both years and for students at all three universities. The differences in the increases among the students at each university are likely due to their varying tasks. For example, Michigan students had the responsibility for making their websites accessible. Washington students were also learning web design principles in their class and were directly involved in the accessible website building process due to their advisory role to the Michigan students as accessible design experts. The Hungarian students were the most removed from this process as they enjoyed the benefits of an accessible website for their businesses but did not contribute directly to developing the accessible structure and content for their website. 
Hungarian students, however, were involved in ensuring that their business plans included accessibility considerations.

\section{Concluding comments and future directions}

Our second-year results are encouraging but they also suggest that some of our changes - particularly the adoption of Moodle as a learning management platform - gave us mixed results. While the Moodle platform offers several accessibility templates, these templates themselves are, ironically, not all that accessible in terms of their accessibility to blind users and the long learning curve they pose to all users. This information was reported by one blind participant in the study. Many of these problems were made explicit to the non-disabled users as well due to the difficulties they experienced in accessing information. One of these difficulties was from the perspective of students with reading and writing disabilities; the Moodle platform in general was confusing for them because Moodle's built-in discussion board did not offer specific landmarks or action markers for locating desired information. Another design issue of the Moodle user interface dwelt in how it presented students' posts as discussion entries without a context. These posts did not specifically speak to a particular person or student group, or at least that is how students read them. Students often failed to realize that they were supposed to respond to the questions raised in the discussion entries, which was not the case in the first year when we used emails directly addressed to team members. It is also possible that we did not build in enough direct instruction about the platform or provide enough sign-posting to guide students in how to use the platform to maximize effectiveness. Although emails are a static medium and appear to be non-interactional, in reality, by the virtue of them being addressed to a specific audience, they elicited a better response from these audiences.

Considering the learning curve issues with Moodle and the irony implicit in the accessibility problems of Moodle's accessibility templates, our plan for the third year of our collaboration is to adopt Google Groups as a platform for communication. The platform organizes group member interactions systematically with an easy to navigate, chronological order and allows all group members (including instructors) to see all messages exchanged within the group. We will also modify our research instrument to study the effects of additional readings about accessibility on the project's overall outcome. The changes in the survey instrument might help us study the crossdisciplinary learning that might take place among the disciplinary curriculum of each of the classes and the added shared curriculum on disability and accessibility.

Through these changes, we hope to further strengthen our collaborative and disability-centered curriculum and improve the effectiveness of our project in increasing students' awareness about 
accessibility. Our goal is to help them learn to design inclusive business plans and websites as we prepare them for a civic and professional life where they can personally ensure inclusivity and equal access. We also hope that instructors invested in issues of equity and inclusion take up international, collaborative, and interdisciplinary projects such as this one because issues around disability and accessibility are very much a part of global conversations on these topics. The United Nations Convention on the Rights of Persons with Disabilities clearly delineates the role that educators must play in providing accessible education and information while contributing to the integration of people with disabilities in our global society (United Nations, 2006). We believe that international virtual exchange projects such as this are well-positioned to ensure that our students learn to design businesses and websites that meet the accessibility needs of persons with disabilities in our societies.

\section{Acknowledgments}

We thank Carine Ullom for all the advice for revising this manuscript through multiple drafts. Without her help, this manuscript would not be what readers have in their hands.

This study has been approved by the Institutional Review Boards at Grand Valley State University and at the University of Washington.

All three authors contributed equally to this manuscript.

Sushil Oswal thanks his son, Hitender Oswal, for his research support.

\section{References}

Americans with Disabilities Act of 1990, Pub. L. No. 101-336, 104 Stat. 328 (1990). https://www.ada.gov/pubs/ adastatute08.htm

Anderson, P., Bergman, B., Bradley, L., Gustafsson, M., \& Matzke, A. (2010). Peer reviewing across the Atlantic: patterns and trends in L1 and L2 comments made in an asynchronous online collaborative learning exchange between technical communication students in Sweden and in the United States. Journal of Business and Technical Communication, 24(3), 296-322. https://doi.org/10.1177/1050651910363270

Belz, A. J. (2005). Intercultural questioning, discovery and tension in internet-mediated language learning partnerships. Language and Intercultural Communication, 5(1), 3-39. https://doi.org/10.1080/14708470508668881 
Blakeslee, A. M. (2001). Bridging the workplace and the academy: teaching professional genres through classroomworkplace collaborations. Technical Communication Quarterly, 10(2), 169-192. https://doi.org/10.1207/ s15427625tcq1002_4

Bueno-Alastuey, M. C., \& Kleban, M. (2016). Matching linguistic and pedagogical objectives in a telecollaboration project: a case study. Computer Assisted Language Learning, 29(1), 148-166. https://doi.org/10.1080/09588221.2014.904360

Creswell, J. W. (2015). A concise introduction to mixed methods research. Sage.

Cunningham, D. J. (2019). Telecollaboration for content and language learning: a genre-based approach. Language Learning \& Technology, 23(3), 161-177. http://hdl.handle.net/10125/44701

Duus, R., \& Cooray, M. (2014). Together we innovate: cross-cultural teamwork through virtual platforms. Journal of Marketing Education, 36(3), 244-257. https://doi.org/10.1177/0273475314535783

Elliott-Gower, S., \& Hill, K. W. (2015). The Soliya Connect Program: two institutions' experience with virtual intercultural. eJournal of Public Affairs, 4(1), 114-140.

European Commission. (2020). Communication from the Commission to the European Parliament, the Council, the European Economic and Social Committee and the Committee of the Regions on achieving the European Education Area by 2025. https://ec.europa.eu/education/sites/education/files/document-library-docs/eea-communicationsept2020_en.pdf

European Political Strategy Centre (2017). 10 trends transforming education as we know it. European Political Strategy Centre. https://op.europa.eu/en/publication-detail/-/publication/227c6186-10d0-11ea-8c1f-01aa75ed71a1

Flick, U. (1998). An introduction to qualitative research: theory, method and applications. Sage.

Garcés, P., \& O’Dowd, R. (2021). Upscaling virtual exchange in university education: moving from innovative classroom practice to regional governmental policy. Journal of International Education, 25(3), 283-300. https://doi. org/10.1177/1028315320932323

Gonzalez-Perez, M. A., Velez-Calle, A., Cathro, V., Caprar, D. V., \& Taras, V. (2014). Virtual teams and international business teaching and learning: the case of the global enterprise experience (GEE). Journal of Teaching in International Business, 25(3), 200-213. https://doi.org/10.1080/08975930.2014.925738

Greene, J., Caracelli, V., \& Graham, W. (1989). Toward a conceptual framework for mixed method evaluation designs. Educational Evaluation and Policy Analysis, 11(3), 255-274.

Guth, S., \& Helm, F. (2010). (Eds). Telecollaboration 2.0: language, literacies and intercultural learning in the 21st century. Peter Lang. https://doi.org/10.3726/978-3-0351-0013-6

Hauck, M. (2019). Virtual exchange for (critical) digital literacy skills development. European Journal of Language Policy, 11(2), 187-211.

Hauck, M., Müller-Hartmann, A., Rienties, B., \& Rogaten, J. (2020). Approaches to researching digital-pedagogical competence development in VE-based teacher education. Journal of Virtual Exchange, 3(SI), 5-35.

Hauck, M., \& Satar, H. M. (2018). Learning and teaching languages in technology-mediated contexts: the relevance of social presence, co-presence, participatory literacy, and multimodal competence. In R. Kern \& C. Develotte (Eds), Screens and scenes: multimodal communication in online intercultural encounters (pp. 133-157). Taylor \& Francis Group. 
Helm, F. (2015). The practices and challenges of telecollaboration in higher education in Europe. Language Learning \& Technology, 19(2), 197-217. https://doi.org/10125/44424

Hernández-Nanclares, N., Mato Díaz, F. J, \& Koris, R. (2019). Expanding higher education classrooms beyond their walls: virtual exchange and challenges for professors. Journal of International Mobility, 7(1), 139-155. https://www.cairnint.info/revue-of-international-mobility-2019-1-page-139.htm

Hersh, M., Leporini, B., \& Buzzi, M. (2020, September). Accessibility evaluation of video conferencing tools to support disabled people in distance teaching, meetings and other activities. In ICCHP (International Conference on Computers Helping People) Open Access Compendium (pp. 133-139). https://re.public.polimi.it/bitstream/11311/1151879/1/ ED_1_ICCHP_Forum.pdf

Jacob, J. W. (2015). Interdisciplinary trends in higher education. Palgrave Communications, 1, 1-5. https://doi.org/10.1057/ palcomms.2015.1

Jauregi, K., De Graaff, R., van den Bergh, H., \& Kriz, M. (2012). Native/non-native speaker interactions through videoweb communication: a clue for enhancing motivation? Computer assisted language learning, 25(1), 1-19.

Koris, R., \& Vuylsteke, J.-F. (2020). Mission (im)possible: developing students' international online business communication skills through virtual teamwork. In F. Helm \& A. Beaven (Eds), Designing and implementing virtual exchange - a collection of case studies (pp. 69-79). Research-publishing.net. https://doi.org/10.14705/ rpnet.2020.45.1116

Leask, B. (2015). Internationalizing the curriculum. Routledge.

Leporini, B., Buzzi, M., \& Hersh, M. (2021, April). Distance meetings during the covid-19 pandemic: are video conferencing tools accessible for blind people? In Proceedings of the 18th International Web for All Conference (pp. 1-10). https://dl.acm.org/doi/abs/10.1145/3430263.3452433

Maylath, B., Vandepitte, S., \& Mousten, B. (2008). Growing grassroots partnerships: trans-atlantic collaboration between American instructors and students of technical writing and European instructors and students of translation. In D. Starke-Meyerring \& M. Wilson (Eds), Designing globally networked learning environments: visionary partnerships, policies, and pedagogies (pp. 52-66). Sense. http://hdl.handle.net/1854/LU-688454

Morse, J. (1991). Approaches to qualitative-quantitative methodological triangulation. Nursing Research, 40, 120-123.

O’Day, B., \& Killeen, M. (2002). Research on the lives of persons with disabilities: the emerging importance of qualitative research methodologies. Journal of Disability Policy Studies, 13(1), 9-15.

O’Dowd, R. (2016). Emerging trends and new directions in telecollaborative learning. CALICO Journal, 33(3), 291-310. https://doi.org/10.1558/cj.v33i3.30747

O'Dowd, R. (2018). From telecollaboration to virtual exchange: state-of-the-art and the role of UNICollaboration in moving forward. Journal of Virtual Exchange, 1, 1-23. https://doi.org/10.14705/rpnet.2018.jve.1

O’Dowd, R., \& O'Rourke, B. (2019). New developments in virtual exchange for foreign language education. Language Learning \& Technology, 23(3), 1-7.

Oswal, S. K. (2013). Ableism - multimodality in motion: disability and kairotic Spaces. Webtext collection. Kairos: A Journal of Rhetoric, Technology, and Pedagogy, 18(1). NP. http://kairos.technorhetoric.net/18.1/coverweb/yergeau-et-al

Oswal, S. K. (2014). Participatory design: barriers and possibilities. Communication Design Quarterly Review, 2(3), 14-19. 
Oswal, S. K. (2018). Can workplaces, classrooms, and pedagogies be disabling? Business and Professional Communication Quarterly, 81(1), 3-19.

Palmer, Z. B., Oswal, S. K., \& Koris, R. (2020). Reimagining business planning, accessibility, and web design instruction: a stacked interdisciplinary collaboration across national boundaries. Journal of Technical Writing and Communication. Advance Online Publication, 1-39. https://doi.org/10.1177/0047281620966990

Roy, N., Schlosser, F., \& Pasek, Z. (2020). Simulating entrepreneurial interest in engineers through and experiential and multidisciplinary course collaboration. Entrepreneurship Education and Pedagogy, 3(1), 14-40. https://doi. org/10.1177/2515127419856602

Sadler, R., \& Dooly, M. (2016). Twelve years of telecollaboration: what we have learnt. ELT Journal, 70(4), 401-413. https://doi.org/10.1093/elt/ccw041

Satar, M. (2020). L1 for social presence in videoconferencing: a social semiotic account. Language Learning \& Technology, 24(1), 129-153.

Spelt, E. J. H., Biemans, H. J. A., Tobi, H., Luning, P. A., \& Mulder, M. (2009). Teaching and learning in interdisciplinary higher education: a systematic review. Educational Psychology Review, 21, 365-378. https://doi.org/10.1007/s10648009-9113-z

Starke-Meyerring, D., \& Andrews, D. (2006). Building a shared learning culture: an international classroom partnership. Business Communication Quarterly, 69(1), 25-49. https://doi.org/10.1177/1080569905285543

Štefl, M. (2019). Virtual exchange across disciplines: telecollaboration and the question of asymmetrical task design. In A. Turula, M. Kurek \& T. Lewis (Eds), Telecollaboration and virtual exchange across disciplines: in service of social inclusion and global citizenship (pp. 91-97). Research-publishing.net. https://doi.org/10.14705/rpnet.2019.35.944

Theofanos, M. F., \& Redish, J. G. (2003). Bridging the gap: between accessibility and usability. Interactions, 10(6), 36-51.

Ullom, C. E. (2017). Developing preservice teacher global citizen identity: the role of globally networked learning. Doctoral dissertation, Fielding Graduate University. ProQuest (10688833).

United Nations. (2006). Convention on the rights of persons with disabilities. Treaty Series, 2515, 3.

Waddington, L., \& Lawson, A. (2010). Disability and non-discrimination law in the European Union: an analysis of disability discrimination law within and beyond the employment field. European Commission. https://doi.org/10.2767/49788

Walshe, N., \& Driver, P. (2019). Developing reflective trainee teacher practice with 360-degree video. Teaching and Teacher Education, 78, 97-105. https://doi.org/10.1016/j.tate.2018.11.009

World Economic Forum. (2016). New vision for education: fostering social and emotional learning through technology. http://www3.weforum.org/docs/WEF_New_Vision_for_Education.pdf

World Wide Web Consortium (2008, December 11). Web Content Accessibility Guidelines 2.0. https://www.w3.org/TR/ WCAG20/

Yu, H. (2010). Bring workplace assessment into business communication classrooms: a proposal to better prepare students for professional workplaces. Business Communication Quarterly, 73(1), 21-39. 


\section{Virtual Exchange?}

Published by University of Groningen Press | UGP, a not-for-profit press

Groningen, The Netherlands | UGP@rug.nl

(C) 2021 UNICollaboration (collective work)

(c) 2021 by Authors (individual work)

Journal of Virtual Exchange 2021

Special issue edited by Carine Ullom and Müge Satar

Publication date: 2021/08/02

Journal of Virtual Exchange (JVE) is an online, open-access, peer-reviewed journal aimed at practitioners and researchers in the field known variously as virtual exchange, telecollaboration, or online intercultural exchange. It is the official journal of UNICollaboration (https://www.UNICollaboration.org/), the international academic organisation dedicated to supporting and promoting telecollaboration and virtual exchange in higher-level education.

Rights. The whole volume is published under the Attribution-NonCommercial-NoDerivatives 4.0 International licence (CC BY-NCND 4.0); individual articles may have a different licence. Under the CC BY-NC-ND licence, the volume is freely available online for anybody to read, download, copy, and redistribute provided that the author(s), editorial team, and publisher are properly cited. Commercial use and derivative works are, however, not permitted.

Disclaimer. University of Groningen Press does not take any responsibility for the content of the pages written by the authors of this article. The authors have recognised that the work described was not published before, or that it was not under consideration for publication elsewhere. While the information in this article is believed to be true and accurate on the date of its going to press, neither UniCollaboration nor University of Groningen Press can accept any legal responsibility for any errors or omissions. Additionally, the publisher makes no warranty, expressed or implied, with respect to the material contained herein. While University of Groningen Press is committed to publishing works of integrity, the words are the authors' alone.

Trademark notice. Product or corporate names may be trademarks or registered trademarks, and are used only for identification and explanation without intent to infringe.

Copyrighted material. Every effort has been made by the editorial team to trace copyright holders and to obtain their permission for the use of copyrighted material in this article. In the event of errors or omissions, please notify the publisher of any corrections that will need to by incorporated in future editions of this article.

Typeset by Research-publishing.net (https://research-publishing.net)

Noto fonts are open source. All Noto fonts are published under the SIL Open Font License, Version 1.1. Noto is a trademark of Google Inc. (https://www.google.com/get/noto/).

ISSN: 2647-4832 (online only)

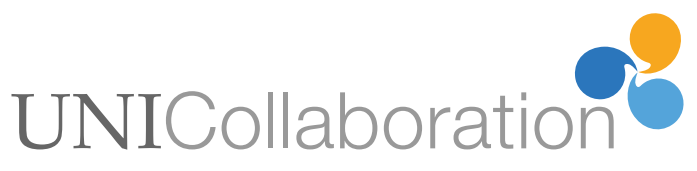

